\title{
Comparative Analysis on the Integration Level of Informatization and Industrialization: Evidence from China
}

\author{
Changqi $\mathrm{Tao}^{1 *}$ and Mengxi $\mathrm{Yu}^{2}$ \\ ${ }^{1}$ School of Information Technology, Jiangxi University of Finance \& Economics \\ ${ }^{2}$ School of Information Technology, Jiangxi University of Finance \& Economics \\ ${ }^{1}$ tcq_822@163.com
}

\begin{abstract}
In the new era, rapid growth of national economy more and more relies on the transformation of industrial structure. Therefore with the in-depth development of industrialization, a very effective way to make our country more prosperous is optimizing industry structure by integration of informatization and industrialization. In this paper, we create a compound synergetic model and use panel data of Jiangxi Province and the country covering the period 2001-2010 to test order degree of the integration. The main results suggest that promoting the synergy degree of intergration would accelerate the economic development. We should make full use of informatization to promote the synergy degree of informatization with industrialization.
\end{abstract}

Keywords: compound synergetic model; informatization; industrialization; integration

\section{Introduction}

In recent years, with the rapid development of China's economy, people's life has continuous improvement. However, along with the deep going of the industrialization, the problem of resources and environment constraint is more and more obvious. How to break the constraining bottleneck in the process of industrialization to rapidly promote China's economic development level has became not only an academic research focus but also the focus of the government. In this context, 16th meeting of the party proposed that the government should promote the traditional industry transformation. New industrialization has many advantages including high technology content, good economic benefits, low resource consumption, little pollution and manpower resources advantages are fully used. Compared to the traditional industrialization of agricultural production taking labor and land as the basic elements, the new type industrialization path has higher quality and more cognition of resource scarcity and environmental pollution than the traditional industrialization path. Vigorously developing the new type industrialization is conductive to break through the bottleneck of resource scarcity and environmental pollution. Therefore, using of information technology's high permeability characteristic, prompting the informatization and coordinated development of new type industrialization has gradually become the focus of more and more scholars. Additionally in the 17th national congress which reflects future trend of economy development in our country, the party put forward "vigorously promote the informatization and industrialization fusion".

As time goes by, integration of informationalization and industrialization has become the mainstream path of economic development which led to gradually increased scholars research in this field both at home and abroad. By far, foreign scholars on the research for integration are mainly focused on how information technologies improve the function of original productions. Information industry technology promotes both production efficiency and economic benefits because of its strong penetration (Bally, 2005) [1]. The integration degree and correlation with enterprise performance were analyzed which confirmed that the higher the degree of electronic information technology integration, the 
enterprise performance was better (Gambardellla and Torrisi, 1998) [2]. Jargenson (2001) found that information industry was an important role to develop the economy of the United States from the interaction of information industry with traditional enterprises [3].

Domestic research of it is even more abundant. Mainly included: First, connotation of integration: Wu Jing-lian (2006) pointed out the development of China's economic future patterns should use information technology to remold the industrial technology [4]. Second, theoretical research in the integration level: Tao Chang-qi (2007) thought that the government should build a synergy mechanism of the fusion and cultivate new industrials in the process of the fusion on the basis of creating an environment which supported for the integration of informatization and industrialization [5]. Chu Sheng (2008) explained the fusion of information technology and industrial production from industrial design, production control, supply logistics, production management and other dimensions [6]. Xie Kang, Xiao Jing-hua and Wu Jia-pei (2009) considered the fusion promoted industrial structure to transform and the economy grow in a path of balancing informationalization and industrialization development and balancing industrial technical resources and information resources [7]. Third, measuring the evaluation of integration: Gong Bingzheng (2008) assessed the fusion situation by evaluating the monomial index and then the comprehensive weighted in the form of a general fusion index method $[8,9]$. Xiao $\mathrm{Xu}$, Sun Jian-hua, and Wang Xi-wei et al., $(2010,2011)$ built indicators for the integration of informationalization and industrialization by using PCA (Principle Component Analysis) $[10,11]$. Xie Kang and Xiao Jing-hua concluded that informatization spurring industrialization was more obviously than path of industrialization promoting informatization through the stochastic frontier approach using Chinese panel data of 31 provinces from 2001 to 2009 [12]. In conclusion, analyzing the integration degree is meaningful because the results are important references in the process of regional economic decision-making.

The rest of the paper is organized as follows: Section 2 presents the theoretical model, and Section 3 describes the empirical analysis and empirical results. Section 4 is the last section which concludes the paper.

\section{Theoretical Model}

\subsection{Connotation of Industrialization and Informatization}

"The fusion of industrialization and informatization" is a new concept which is a trend in today's world and deep analysis and accurate judgment of our country, also comprehensive summary of historical experience and lessons on the basis of correct forecast, reveals and accurate positioning of China's law of development. The ultimate goal of the fusion is, "a new path of high technological content, good economic benefits, low resources consumption, little environmental pollution and human resources superiority obtains give full play to new type industrialization", but how to walk, is a brand new subject. From the point of history and reality, from the point of vertical and horizontal, the fusion of informatization and industrialization is a theoretical breakthrough, which is also a technical innovation, and a comprehensive system engineering, must be conducted on its past, present, and future comprehensive system research.

2.1.1. Industrialization and New Industrialization: Industrialization is from Britain in the 1760s, the logo is the popularity of the appearance of machine manufacturing and mechanization of production. "Industrialization" is usually defined as industry or the second industry output value proportion in the gross national product (GNP) the rising process. The party's 16 big reports put forward that the road of new type industrialization. New industrialization is to stick to drive industrialization by informatization which means industrialization promotes informatization, namely high technological content, good 
economic benefits, low resources consumption, little environmental pollution, human resources, give full play to the industrialization.

2.1.2. Informatization: Informatization is started from the United States in the 1950s; the logo is the combination of computers and telecommunications information network popularization. Informationization refers to maximize the use of information resources to meet the information demands of the whole society under the guidance of national macro policies through the information technology development, the development of information industry and information talent configuration to promote industrial structure optimization and upgrading gradually sustained and rapid development of national economy, to complete the process of transition from industrial society to information society. Information level has become the measure of a country, a city or region in terms of comprehensive strength and international competitiveness and the important mark of the modernized level.

Measure the informationization degree of index usually has the following five points: one is the richness of information resources, the second is information network transmission of network, the third is the wide application of information technology, the fourth is the popularization of information technology, last is the proportion of information industry in the national economy.

\subsection{Composite Synergy Model}

It was clearly stated in 16th national congress that new industrialization was an industrialized development path with advantages of high technology content, good economic benefits, low resource consumption, little environment pollution and manpower resources. The process of informatization is complex which is about the popularization and application of information technology from a technical perspective; the growth of information industry from the industry level; the contribution degree of information industry to national economy from a macro perspective. Hence informatization is a dynamic evolution process from industrial economy to informatization economy and from industry society to informatization society. In the process of the integration, we should measure industrialization from science content, economic benefits, resource condition, manpower resource and other features; measure informatization from resource utilization, internet construction, technology promotion, development conditions, talent construction and other features.

The integration of informatization and new industrialization is an extremely process through the positive effect and the adverse effect. On the one hand, with the rapid development of information industry, the emerging technologies are seeping through in the traditional industry production, management, sales and other fields by means of technology integration, product integration and business integration; on the other hand, traditional industries have feedback effects to the development of information technology which would influence the development direction of information technology. Therefore, to a certain extent, the integration of informatization and industrialization can be regarded as two branches of a larger evolution system which would adjust the synergy degree of the system through overlapping influence, in turn promote the development of the whole system.

Through the above mentioned analysis, we can analyze the integration of informatization and industrialization from synergetic theory aspect. Synergy theory was suggested by the German famous physicist Haken which was mainly about the interaction between subsystems in a larger system's evolution process. We use the coordination model from industry innovation and industry collaborative research (Tao Chang-qi, Qi Ya-wei, 2009) [13], and consider the interaction between informatization and industrialization as a compound system. We divide the whole 
compound system into informatization subsystem and new industrialization subsystem. According to the connotation of new industrialization, we select the measuring indicators of new industrialization subsystem. For the informatization subsystem, we mainly criticize from the utilization of information resources, construction of information internet, application of information technology, development of information industry and construction of talent aspects according to National informatization index system and Regional informatization index system (Zhao Guo-jie, 2009) [14].

\subsection{Order Degree Model of the Subsystem}

Assuming the order parameter is $q=\left(q_{11}, q_{12}, \cdots, q_{1 n}\right)$ in the process of the integration, and $n \geq 1, \beta_{1 i} \leq q_{1 i} \leq \alpha_{1 i}, i \in[1, n]$. In this paper, the order parameter of the integration of informatization and industrialization can be regarded as various evaluation indicators. Assuming that $q_{11}, q_{12}, \cdots, q_{1 j}$ are slow relaxation parameters whose values are directly proportional to the order degree of the whole system; and fast relaxation parameters are $q_{1 j+1}, q_{1 j+2}, \cdots, q_{1 n}$ whose values are inversely proportional to the order degree of the whole system. The order degree of the system has the following definitions:

Definition 1: $u_{1}\left(q_{1}\right)$ is the order degree of $q_{1}$ order parameter in the subsystem, counted as:

$$
u_{1}\left(q_{1}\right)=\left\{\begin{array}{l}
\frac{q_{1 i}-\beta_{1 i}}{\alpha_{1 i}-\beta_{1 i}}, i \in[1, j] \\
\frac{\alpha_{1 i}-q_{1 i}}{\alpha_{1 i}-\beta_{1 i}}, i \in[j+1, n]
\end{array}\right.
$$

From the above definition, we know $u_{1}\left(q_{1}\right) \in[0,1]$, also we can know the bigger the value of it the higher the contribution rate of order parameter $q_{1}$ to the subsystem. From overall perspective, we can calculate the contribution rate of the order parameter to whole industry integration through geometric average method or linear weighted summation method. In this paper, we use linear weighting method, which is as below:

$$
U_{1}\left(q_{1}\right)=\sum_{j=1}^{n} \omega_{j} u_{1}\left(q_{1}\right) \quad\left(\omega_{j} \geq 0, \sum_{j=1}^{n} \omega_{j}=1\right)
$$

Definition 2: Defined $u_{1}\left(q_{1}\right)$ from (2) is the order degree of order parameter $q_{1}$.

From above definitions, we know that the bigger order parameter of subsystem 1 the higher contribution rate of order degree to the whole compound system. Similarly, order parameter of subsystem2 is $q_{2}=\left(q_{21}, q_{22}, \cdots, q_{2 n}\right)$, and $n \geq 1, \beta_{2 i} \leq q_{2 i} \leq \alpha_{2 i}, i \in[1, n]$. Then we know the order degree of subsystem 2 is $U_{2}\left(q_{2}\right)$.

\subsection{Coordination Degree Model of the Compound System}

Definition 3: Assuming in infancy $t_{0}$, the order degree of industrialization system is $U_{1}{ }^{0}\left(q_{1}\right)$, and the order degree of informatization system is $U_{2}{ }^{0}\left(q_{2}\right)$; to the later stage $t_{1}$ after the integration, the order degree of industrialization system is $U_{1}{ }^{1}\left(q_{1}\right)$, and the order 
degree of informatization system is $U_{2}{ }^{1}\left(q_{2}\right)$. Then we define the below equation as the synergy degree of the integration system:

$$
\begin{gathered}
\mathrm{X} T D=\eta \sqrt{\left|U_{1}{ }^{1}\left(q_{1}\right)-U_{1}{ }^{0}\left(q_{1}\right)\right| \cdot\left|U_{2}{ }^{1}\left(q_{2}\right)-U_{2}{ }^{0}\left(q_{2}\right)\right|} \\
\eta=\min _{i}\left[U_{i}{ }_{i}^{1}\left(e_{m}\right)-U_{i}{ }^{0}\left(e_{m}\right) \neq 0\right] /\left|\min _{i}\left[U_{i}{ }^{1}\left(e_{m}\right)-U_{i}{ }^{0}\left(e_{m}\right) \neq 0\right]\right|
\end{gathered}
$$

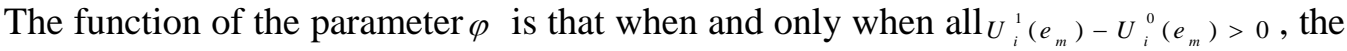
integration system would have positive synergy degree. When there exists a negative value, the subsystem will show changes in opposite directions meaning its absence of positive coordination.

\section{Empirical Analysis}

\subsection{Evaluation Indicators}

Domestic researched evaluation index system of the integration of informatization and industrialization mostly, also evaluation standard proposed were not the same. Such as Dai Jun, Huang Xiu-qing. (2011) respectively suggested the fusion index of informatization and new industrialization from the informatization environment, application innovation and effect efficiency aspect [15]. Hao Hua-yong (2012) proposed an evaluation criterion of provincial new industrialization [16].

We built an indicator system with different kinds of indicators to measure the whole system based on domestic scholars' study (Zhang Xue-gang, Fu Shuai-xiong, 2009) [17]. The collaborative systems of informatization and new industrialization include two subsystem named the new industrialization system and informatization subsystem. Both of the subsystems are made up of first-class indicators and second-class indicators. The first subsystem has five first-class indicators including industrialized operation condition, technology content, economic benefits, HR utilization and resource environment state. And the second subsystem has five first-class indicators, as below the Table 1:

\begin{tabular}{|c|c|c|c|}
\hline System & Subsystem & $\begin{array}{l}\text { First-class } \\
\text { indicator }\end{array}$ & Second-class indicator \\
\hline \multirow{13}{*}{$\begin{array}{c}\text { Collaborative } \\
\text { systems of } \\
\text { informationalizati } \\
\text { on and new } \\
\text { industrialization }\end{array}$} & \multirow{13}{*}{$\begin{array}{c}\text { New } \\
\text { industrialization } \\
\text { subsystem }\end{array}$} & \multirow{3}{*}{$\begin{array}{l}\text { Industrialized } \\
\text { operation } \\
\text { condition }\end{array}$} & GDP \\
\hline & & & GDP per capita \\
\hline & & & Industrial added value \\
\hline & & \multirow{2}{*}{$\begin{array}{l}\text { Industrialized } \\
\text { technology } \\
\text { content }\end{array}$} & Annual R\&D spending \\
\hline & & & Granted patent approval \\
\hline & & \multirow{3}{*}{$\begin{array}{l}\text { Industrialized } \\
\text { economic } \\
\text { benefits }\end{array}$} & Total industrial profits \\
\hline & & & $\begin{array}{c}\text { Total assets contribution of industrial } \\
\text { enterprises }\end{array}$ \\
\hline & & & Enterprise cost efficiency \\
\hline & & \multirow{2}{*}{ HR utilization } & $\begin{array}{l}\text { Employment figure in secondary } \\
\text { industry }\end{array}$ \\
\hline & & & $\begin{array}{l}\text { Full employment in industrial } \\
\text { enterprises }\end{array}$ \\
\hline & & \multirow{3}{*}{$\begin{array}{c}\text { Resource } \\
\text { environment } \\
\text { state }\end{array}$} & Drainage of industrial wastewater \\
\hline & & & Industrial SO2 emissions \\
\hline & & & Annual energy consumption \\
\hline
\end{tabular}

Table 1. Indicator System of Collaborative Systems 


\begin{tabular}{|c|c|c|}
\hline \multirow{13}{*}{$\begin{array}{c}\text { Informationalizati } \\
\text { on } \\
\text { subsystem }\end{array}$} & \multirow{3}{*}{$\begin{array}{l}\text { Utilization of } \\
\text { information } \\
\text { resources }\end{array}$} & Capacity of mobile telephone exchanges \\
\hline & & Capacity of LAN telephone exchanges \\
\hline & & $\begin{array}{c}\text { Capacity of long-distance telephone } \\
\text { exchanges }\end{array}$ \\
\hline & \multirow{3}{*}{$\begin{array}{c}\text { Construction of } \\
\text { information } \\
\text { internet }\end{array}$} & Radio population coverage \\
\hline & & Population coverage on TV \\
\hline & & Line length of toll cable \\
\hline & \multirow{2}{*}{$\begin{array}{c}\text { Application of } \\
\text { information } \\
\text { technology }\end{array}$} & Amount of local telephone users \\
\hline & & Internet population \\
\hline & \multirow{3}{*}{$\begin{array}{c}\text { Development of } \\
\text { information } \\
\text { industry }\end{array}$} & Telephone service traffic \\
\hline & & $\begin{array}{l}\text { Fixed assets investment in P\&T } \\
\text { Industry }\end{array}$ \\
\hline & & $\begin{array}{c}\text { Information, computer, software } \\
\text { investment }\end{array}$ \\
\hline & \multirow{2}{*}{\begin{tabular}{c|} 
Excavation of \\
information \\
talents
\end{tabular}} & Employment in electronic industry \\
\hline & & $\begin{array}{c}\text { Employment in telecommunications } \\
\text { industry }\end{array}$ \\
\hline
\end{tabular}

\subsection{Data Sources}

We select the data including the panel data of China and Jiangxi Province from 2001 to 2010. The required data comes from China Statistical Yearbook, Chinese Economy Database, Chinese Science Statistical Yearbook, national economy data in Jiangxi Province and Society Developed Statistical bulletin.

\subsection{Weighing Order Parameter Indicators \& Related Calculation}

In the model, each index weight means its influential degree to the whole system. At present, there are many kinds of empowerment approach such as based on experience value, information entropy and subordinating degree function using fuzzy mathematics. In this paper we use correlation matrix method for empowerment to calculate. Basic steps are as follows: Assuming the indicator system including $\mathrm{n}$ indicators, and their correlation matrix are $R=\left[\begin{array}{ccc}r_{11} & \cdots & r_{1 n} \\ \cdots & \cdots & \cdots \\ r_{n 1} & \cdots & r_{n n}\end{array}\right]$, hereinto all elements on the primary diagonal are 1 which means $r_{11}=r_{22}=\cdots r_{i i}=r_{n n}=1$.

$$
R_{i}=\sum_{i=1}^{n}\left|r_{i j}\right|-1 \quad(i=1,2, \cdots, n)
$$

Using the normalization method we can get corresponding indicator weight as below:

$$
\omega_{i}=R_{i} / \sum_{i=1}^{n} R_{i} \quad(i=1,2, \cdots, n)
$$

On account of inconformity of data units, we should process the data using standardized method. And utilizing (4) and (5) to calculate national index weight of informatization and new industrialization and Jiangxi index weight of informatization and new industrialization as below in Table 2, Table 3, Table 4, and Table 5: 
Table 2. National Index Weight Table of New Industrialization

\begin{tabular}{cccccccc}
\hline Index & 1 & 2 & 3 & 4 & 5 & 6 & 7 \\
Weight & 0.0809 & 0.0809 & 0.0810 & 0.0810 & 0.0780 & 0.0802 & 0.0744 \\
\hline Index & 8 & 9 & 10 & 11 & 12 & 13 & - \\
Weight & 0.0606 & 0.0798 & 0.0800 & 0.0611 & 0.0817 & 0.0805 & - \\
\hline
\end{tabular}

Table 3. Jiangxi Index Weight Table of New Industrialization

\begin{tabular}{cccccccc}
\hline Index & 1 & 2 & 3 & 4 & 5 & 6 & 7 \\
Weight & 0.0805 & 0.0806 & 0.0798 & 0.0794 & 0.0768 & 0.0807 & 0.0790 \\
\hline Index & 8 & 9 & 10 & 11 & 12 & 13 & - \\
Weight & 0.0805 & 0.0803 & 0.0803 & 0.0766 & 0.0508 & 0.0808 & - \\
\hline
\end{tabular}

Table 4. National Index Weight Table of Informatization

\begin{tabular}{cccccccc}
\hline Index & 1 & 2 & 3 & 4 & 5 & 6 & 7 \\
Weight & 0.0811 & 0.0707 & 0.791 & 0.0843 & 0.0843 & 0.0788 & 0.0532 \\
\hline Index & 8 & 9 & 10 & 11 & 12 & 13 & - \\
Weight & 0.0796 & 0.0830 & 0.0775 & 0.0769 & 0.0687 & 0.0828 & - \\
\hline
\end{tabular}

Table 5. Jiangxi Index Weight Table of Informatization

\begin{tabular}{cccccccc}
\hline Index & 1 & 2 & 3 & 4 & 5 & 6 & 7 \\
Weight & 0.0853 & 0.0872 & 0.09 & 0.0927 & 0.0937 & 0.0912 & 0.0709 \\
\hline Index & 8 & 9 & 10 & 11 & 12 & 13 & - \\
Weight & 0.0839 & 0.0896 & 0.0858 & 0.0041 & 0.032 & 0.0935 & - \\
\hline
\end{tabular}

\subsection{Synergy Degree Calculation of the Compound System}

According to (1) and (2), we can calculate the indicators of informatization and new industrialization for both the nation and Jiangxi Province respectively. Then, we can get the results the integration of informatization and industrialization of both the country and Jiangxi Province respectively which include the order degree of informatization, the order degree of new industrialization and synergy degree from 2001 to 2010. Results are shown as below in Table 6 and Table 7:

Table 6. National Order Degree and Synergy Degree Results

\begin{tabular}{cccc}
\hline Year & $\begin{array}{c}\text { Oder degree of } \\
\text { Industrialization }\end{array}$ & $\begin{array}{c}\text { Oder degree of } \\
\text { Informatization }\end{array}$ & $\begin{array}{c}\text { Synergy } \\
\text { degree }\end{array}$ \\
\hline 2001 & 0.2305 & 0.0011 & - \\
2002 & 0.2467 & 0.0879 & 0.0376 \\
2003 & 0.3007 & 0.2049 & 0.1197 \\
2004 & 0.3472 & 0.3184 & 0.1924 \\
2005 & 0.3621 & 0.4058 & 0.2308 \\
2006 & 0.4627 & 0.5176 & 0.3463 \\
2007 & 0.5119 & 0.6265 & 0.4195 \\
2008 & 0.5484 & 0.6949 & 0.697 \\
2009 & 0.6203 & 0.9055 & 0.5937 \\
2010 & 0.7896 & 0.9387 & 0.7241 \\
\hline
\end{tabular}


Table 7. Jiangxi Order Degree and Synergy Degree Results

\begin{tabular}{cccc}
\hline Year & $\begin{array}{c}\text { Oder degree of } \\
\text { Industrialization }\end{array}$ & $\begin{array}{c}\text { Order degree of } \\
\text { Informatization }\end{array}$ & $\begin{array}{c}\text { Synergy } \\
\text { degree }\end{array}$ \\
\hline 2001 & 0.2066 & 0.0062 & - \\
2002 & 0.2288 & 0.1542 & 0.0573 \\
2003 & 0.2560 & 0.2387 & 0.1072 \\
2004 & 0.2784 & 0.3202 & 0.1512 \\
2005 & 0.3145 & 0.4709 & 0.2239 \\
2006 & 0.3609 & 0.6194 & 0.3076 \\
2007 & 0.4445 & 0.6826 & 0.4011 \\
2008 & 0.5794 & 0.7388 & 0.5226 \\
2009 & 0.6288 & 0.8605 & 0.6005 \\
2010 & 0.8073 & 0.9298 & 0.7448 \\
\hline
\end{tabular}

\section{Conclusions and Policy Recommendations}

\subsection{Conclusions}

In theory, the contribution of Jiangxi Province's informatization order degree to whole compound system is higher than new industrialization in the composite synergy model of Jiangxi integration of informatization and industrialization. In practice, there are many reasons causing the above results, for example historical reasons, weak modern industry foundation and slow development of Jiangxi Province.

At the end of 2001, Jiangxi Province had established the "Rising in the central region of Jiangxi" strategic objective, and proposed the " 3 bases, 1 back garden" strategic thinking, and taking location advantage of adjacent to "Yangtze river delta, the pearl river delta, Fujian" three Economic Zone, then considering industry development as the core thinking. In 2003, the provincial industry ratio was the top 1 among each industry of national economy for the first time, by which time Jiangxi Province turned traditional agricultural province to a big industrial province. In 2006, Jiangxi Province proposed "storm plan in 3years". By implementing storm industrial projects in Jiangxi Province since 2007, remarkable results in promoting the new type industrialization path have been achieved. Photovoltaic industry has been developed rapidly which formed a photovoltaic industry chain from silicon, silicon slice to solar cell components in just few years. However, most of the industries still have such problem like poor foundation, huge resource consumption, serious environmental pollution which would constrain the future development of Jiangxi Province's economy. Therefore, promoting new type industrialization has become the only way of future economic development of Jiangxi Province. In 2007, the industrialization level rapidly promoted. And in 2009, Jiangxi Province put forward 10 strategic emerging industrials at national scale. Jiangxi understanding early the importance of informatization to provincial economy led to a good result of promoting informatization throughout the province.

\subsection{Policy Recommendations}

The fusion of industrialization and informatization promotes the development of industries and lays a foundation for our country to enter the post-industrial era. Our country is in the crucial stage of accelerated development of industrialization and takes a new path to new type industrialization, promoting the fusion and facilitating new technology combined with traditional industrial is an important task of the current and future period which can lead the industry more strong. Information technology is the 
dominant technology among modern technologies. The full application of information technology into industrial production becomes the inevitable choice to promote the industrial development in our country and industrial competition level in our country.

And the integration of informatization and industrialization is a long and complex process. Therefore, it requires multiple participants working together to promote the integration degree of informatization and new industrialization. Thus we give the following five suggestions:

First, lifting the height of the fusion strategy, strengthen the guide of government, creating good environment for integration. The government should attach great importance to integration of the two in promoting economic growth; perfect related laws and regulations; optimize the fusion environment;

Second, speeding up the technical innovation of industrial enterprise, strengthen enterprise consciousness, improving the inner motive power of enterprises. Related specification should be published to inspire the enterprises using information technology and leading small and medium-sized enterprises perfect their internal informatization construction for the purpose of improving economic profits;

Third, increasing the intensity of cultivating electronic information talents, lifting the ratio of electronic industry to national economy. Also the relevant departments should establish related system to attract information industry talents. Thus it can lead to widely application of electronic information technology;

Fourth, the government should intensify cultivating the strategic emerging industries such as photovoltaic, bio-pharmaceutical, aviation manufacturing and other industries and promote the development of new industrialization in Jiangxi Province with strategic emerging industries as main power;

Last, relevant departments should construct a communication platform which includes the enterprises, colleges and universities, scientific research institution and government departments. On the one hand, it can promote the application of information technology in the production and operation of enterprises; on the other hand, it can provide required feedback effects of using information technologies which leads to information technology innovations.

\section{Acknowledgements}

This work is sponsored Research Project: the research is sponsored by the National Nature Science Foundation of China $((71073073,71273122,71473109,41461025)$ and Jiangxi Social Science Project in the "twelfth five-year" Plan ([2007] 13YJ26). The authors are grateful for the anonymous reviewers who made constructive comments.

\section{References}

[1] N. Bally, "Deriving Managerial Implications from Technological Convergence along the Innovation Process: A Case Study on the Telecommunications Industry", Swiss Federal Institute of Technology (ETH Zürich), (2005).

[2] A. Gambardella and S. Torrisi, "Does Technological Convergence Imply Convergence in Markets?", Evidence from the Electronics Industry, Research Policy, vol. 27, no. 5, (1998), pp. 445-463.

[3] D. W. Jargenson, "Information Technology and the US Economy", American Economic Review, vol. 91, no. $1,(\mathbf{2 0 0 1})$.

[4] W. Jing-lian, "Which industrialization path should China choose?", Management World, vol. 8, (2006), pp. $15-21$.

[5] T. Chang-qi, "Promote the integration of informatization and industrialization; enhance the power of industrial development", vol. 06, (2007), pp. 28-32.

[6] Z. Sheng, "Connotation, difficulties and countermeasures of the integration between informationalization and industrialization", Electrical Engineering Technology, vol. 07, (2008), pp. 1923.

[7] X. Kang, X. Jing-hua and W. Jia-pei, "Environment, basis and path of the integration of informationalization and industrialization in China", Economic Perspectives, vol. 02, (2009), pp. 32-41. 
[8] G. Bing-zheng, "Evaluation and the method discussed in integration of informatization and industrialization”, China Information Times, vol. 08, (2008), pp. 21-24.

[9] G. Bing-zheng, "Evaluation index and method of integration of informatization and industrialization", China Information Times, vol. 11, (2008), pp. 26-33.

[10] X. Xu and S. Jian-hua, "Based on principle component analysis of systems and mechanisms for Liaoning Province two fusion research contribution", Mathematics in Practice and Theory, vol. 18, (2010), pp. 48-54.

[11] W. Xi-wei, A. Chao and C. Yi, "Evaluation index and method study of integration of informationalization and industrialization", Library and Information Service, vol. 06, (2011), pp. 16-22.

[12] X. Kang, X. Jing-hua, Z. Xian-bo and W. Jia-pei, "China's integration quality of informatization and industrialization: theory and practice", Economy Research, vol. 01, (2012), pp. 21-24.

[13] T. Chang-qi and Q. Ya-wei, "Under the integration background of the information industrial innovation and industrial system the synergy mechanism of growth", Science of science Management of S\&T, vol. 11, (2009), pp. 36-41.

[14] S. Li-jie, Z. Guo-jie and L. Yang, "Measures of informationalization level and study on the relationship with the economic growth", Science Management Research, vol. 03, (2009), pp. 31-39.

[15] D. Jun and H. Xiu-qing, "Fusion level assessment system to explore of informationalization and industrialization", Fusion and development of the Internet academic paper, (2010).

[16] H. Hua-yong, "Based on the fusion of provincial new industrialization level assessment and countermeasures", Economy and Management, vol. 01, (2012), pp. 29-35.

[17] Z. Xue-gang and F. Xiong-shuai, "New industrialization process measurement and evaluation of Inner Mongolia", China Markets, vol. 29, (2011), pp. 18-24.

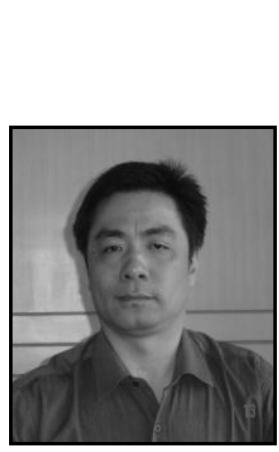

\section{Authors}

Changqi Tao, (1967.8-) bored in Linchuan, Jiangxi Province, P.R. China, professor, doctoral supervisor, his research interest is in quantitative economics, at present he works in School of Information Technology, Jiangxi University of Finance \& Economics.

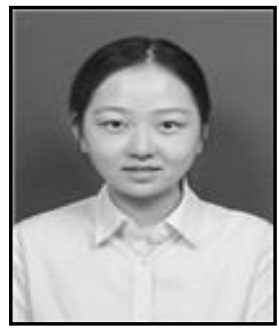

Mengxi Yu, (1991.5-) bored in Jingdezhen, Jiangxi Province, P. R. China, graduate student, her major is in quantitative economics, at present she studies in School of Information Technology, Jiangxi University of Finance \& Economics under the guidance of Professor Changqi Tao. 